\title{
The effect of the Quran recitation on mental health of the Iranian medical staff
}

\author{
Morteza Darabinia, Ali Morad Heidari Gorji , Mohammad Ali Afzali \\ Mazandaran University of Medical Sciences, Sari, Iran
}

Received: April 30, 2017

Accepted: June 6, 2017

Online Published: June 18, 2017

DOI: $10.5430 /$ jnep.v7n11p30

URL: https://doi.org/10.5430/jnep.v7n11p30

\begin{abstract}
This study was conducted with aim of determine the effect of the Quran recitation on mental health of the medical staff of Mazandaran University of Medical Sciences (Sari, Iran). This quasi-experiment study was done in 2016. According to same study 80 medical staff of Mazandaran University of medical sciences (Mazandaran, Iran) were gathered according to inclusion criteria's. Inclusion criteria's were (i) complete satisfaction to study, (ii) no having mental or physical disorders. In case of emergency events participants were excluded from study. Then participants randomly distributed to two groups ( 40 participants in control and experimental group). Experimental group listened to some verses of the Holy Quran for 3 months at the beginning of each working day for 3 minutes, while the control group didn't receive the Quran recitation. The findings showed that $45 \%$ of staffs were male and $55 \%$ of staffs were women. The average age of staffs was $44.87 \pm 3.56$. The mean of mental health and all its domains, after hearing the verses of the Quran, in experimental group was higher than the control group $(p<.05)$. Also women indicated a higher average score than men on mental health, behavioral and socio emotional domains. As a final conclusion and on the basis of the findings of this study; it can be said, particularly in Muslim communities, hearing the Quran recitations improves the mental state of the people. Therefore, it is recommended to use the Quran recitations to reinforce positive emotions and psychological comfort for Muslim staffs.
\end{abstract}

Key Words: Mental health, University staff, Quran, Iran

\section{INTRODUCTION}

Mental health in human beings is defined as emotional and psychological health ${ }^{[1,2]}$ according to the definition of World Health Organization (WHO) it is a state of relaxation and comfort in which the person identifies his/her own abilities and can cope with the natural and normal pressures of life. ${ }^{[3]}$ Nowadays, mental disorder is considered to be the most common psychiatric disorder of the twentieth century and one of the major problems of communities. Concerning the etiology of this disorder, the spiritual perspective as well as biological, psychological and social views is universally accepted. ${ }^{[4-6]}$
Religious teachings are useful tools for the human beings, which result in better and more transcendent understanding of life and eventually cause satisfaction in their lives and jobs. ${ }^{[7-9]}$ Connection with God, can be a different experience in dealing with anxiety and depression, exerting positive results. ${ }^{[10,11]}$ Spiritual understanding arising from people's mental health results in an awareness of facts, values, credibility and ethics. ${ }^{[12,13]}$ The Quran recitation is considered as a religious coping behavior and it is of particular importance in Muslim communities. ${ }^{[10]}$ God's words affect the spirit in a way that after hearing it, feeling of lightness, vitality and freedom from the bondages of the material world is induced

*Correspondence: Ali Morad Heidari Gorji; Email: alifar_2004@yahoo.com; Address: The Education Development Center, Mazandaran University of Medical Sciences, Sari, Iran. 
in human beings. The healing power of the Quran refers to both mental and physical health. ${ }^{[14,15]}$ As, Mohammad prophet introduced Quran as God's words and Islam miracle. Psychologists of Egbal Lahoori University of Pakistan ${ }^{[16]}$ Showed that treating depression through praying to God and reading Quran versus in 78 percent of treatment group was effective and the Comparison group which stay late at high to pray to God shows only 15 percent improvements of depression. Boalhry and Ferrand (1995) in the research with the name of Quran and the ways of preventing mental pressures came to the conclusion that Quran introduces some ways to prevents mental pressures. ${ }^{[17]}$ Those ways are praying to God, patience, repent, talking to God, thinking about those things which are ever ending and getting away from permanent things. Hassanpour and Loya (1997) indicated that teen's high school students who recite Quran regularly have less depression, anxiety and stress than the other Comparison groups who do not recite Quran regularly. ${ }^{[18]}$ Jafari and Moosavi (1997) showed that hawing insisted read Quran regularly; female University students have a few degree of stress. ${ }^{[19]}$ Galedar and Saki (2001) showed in their study that those who listen to Quran at the time of Azan, they have a few degree of stress than their contrast groups who do not listen to Quran. ${ }^{[20]}$ Hence, the Quran not only has provided general guidelines for the attainment of peace, but also has provided strategies as practical measures like listening to the revelation, recitation, attention, trust, resort, reflection, patience or self-control, resilience that can increase mental health. ${ }^{[21]}$ This is more important for medical staff; because good mental health help staffs to work effectively. ${ }^{[22]}$ Also medical staffs including nurses that always facing with the work pressure and patients had a high risk for catching the mental disorders. ${ }^{[23]}$ So these fields of studies have advantage for helping to decrease these mental disorders in them.

According to available databases, there were no previous studies about this topic in medical staff of Iran that was done as experimental method. So this study was conducted with aim of determine the effect of the Quran recitation on mental health of the medical staff of Mazandaran University of Medical Sciences.

\section{MethodS}

This quasi-experiment study was done in 2016. According to same study, ${ }^{[16]} 80$ medical staff of Mazandaran University of medical sciences (Mazandaran, Iran) were gathered randomly according to inclusion criteria's. Inclusion criteria's were (i) complete satisfaction to study, (ii) absence of acute and chronic physical and mental illnesses (examined by the group's psychologist). In case of (i) emergency events (unpredictable disease or transfer the staffs), and (ii)

Published by Sciedu Press absence more than 2 sessions from training classes (none of the staffs were included in the exclusion rules) participants were excluded from study.

\subsection{Outcome measure}

To data gathering a researcher made questionnaire was used. The questionnaire has four parts included demographic characteristics (such as age, gender, education, etc) and the 3 domains including behavioral, cognitive and socio emotional. The questionnaire has a total of 18 items. So that each area contained 6 questions and the subjects were asked to choose one of the five options (Likert scale) of very high, high, medium, low and very low to respond to each question. For content validity the questionnaire was distributed to $10 \mathrm{ex}$ perts of associated university of medical sciences and asked them to write their opinion and revision comments about items of questionnaire. Then questionnaire was modified based on expert's comments. Reliability of the questionnaire was assessed with Cronbach's alpha on medical staffs and was proved in 0.84 .

\subsection{Interventional method}

Then participants randomly distributed to two groups (40 participants in control and experimental group). The test group listened to the Quran as Tartil recitation for 3 min every morning for a period of 3 months. The voice Quran reader was broadcast through the building's speakers from 8:15 until 8:18 AM. The reader voice and Quran verses were chosen randomly. After finishing the test, the participants completed the mental health questionnaire. The control group didn't receive the Quran recitation.

\subsection{Ethical considerations}

This study was conducted in accordance to the conventions laid out within the Helsinki Statement. ${ }^{[24]}$ All procedures performed in studies involving human participants were identical to the ethical standards of the institutional and/or national research committee. The study protocol was approved by the ethics committee of Mazandaran University of Medical Sciences.

\subsection{Statistical analysis}

Data recording and analysis were performed using SPSS version 17.0 software (SPSS Inc., Chicago, IL). Normality of data was assessed by Kolmogorov-Smirnov test (normality was proved on $p=.52$ ). Independent $\mathrm{t}$-test was used to assess the differences of mental health score between control and experimental group. To detecting the probable association among demographic and mental health score chi-square was used. We used the analysis of variance (ANOVA) to investigate the effects of age on mental health. 


\section{Results}

The findings showed that $45 \%$ of staffs were male and $55 \%$ of staffs were women. The average age of staffs was 44.87 \pm 3.56 . The experimental and control groups were matched together in terms of demographic characteristics (such as gender, age, marital, residence and employment status) and no significant difference was observed between the two groups $(p>.05)$.

Table 1. Comparison of mental health and its components in the experimental and control groups (before and after hearing the verses of the Quran)

\begin{tabular}{|c|c|c|c|c|c|c|}
\hline Domain & Test & Group & Mean & SD & $T$ test & $p$ \\
\hline \multirow{4}{*}{ Cognitive } & \multirow{2}{*}{ Before } & Experimental & 17.05 & 2.18 & \multirow{2}{*}{1.71} & \multirow{2}{*}{.34} \\
\hline & & Control & 16.85 & 2.34 & & \\
\hline & \multirow{2}{*}{ After } & Experimental & 22.36 & 2.57 & \multirow{2}{*}{-6.88} & \multirow{2}{*}{$.000^{*}$} \\
\hline & & Control & 17.1 & 2.65 & & \\
\hline \multirow{4}{*}{ Behavioral } & \multirow{2}{*}{ Before } & Experimental & 18.12 & 1.10 & \multirow{2}{*}{1.45} & \multirow{2}{*}{.12} \\
\hline & & Control & 16.85 & 2.34 & & \\
\hline & \multirow{2}{*}{ After } & Experimental & 22.36 & 2.57 & \multirow{2}{*}{-4.09} & \multirow{2}{*}{$.001 *$} \\
\hline & & Control & 18.44 & 1.42 & & \\
\hline \multirow{4}{*}{ Socio- emotional } & \multirow{2}{*}{ Before } & Experimental & 15.95 & 2.65 & \multirow{2}{*}{1.01} & \multirow{2}{*}{.61} \\
\hline & & Control & 16.12 & 2.54 & & \\
\hline & \multirow{2}{*}{ After } & Experimental & 20.85 & 1.71 & \multirow{2}{*}{-2.013} & \multirow{2}{*}{$.019 *$} \\
\hline & & Control & 16.32 & 1.64 & & \\
\hline \multirow{4}{*}{ Mental health } & \multirow{2}{*}{ Before } & Experimental & 51.12 & 2.36 & \multirow{2}{*}{0.48} & \multirow{2}{*}{.10} \\
\hline & & Control & 51.33 & 2.21 & & \\
\hline & \multirow{2}{*}{ After } & Experimental & 66.8 & 1.97 & \multirow{2}{*}{-6.12} & \multirow{2}{*}{$.001^{*}$} \\
\hline & & Control & 51.86 & 2.67 & & \\
\hline
\end{tabular}

$* p<.05$

According to the data of Table 1, mental health's score and all its domains in the control group, after hearing the Quran, had significant changes. The difference between the control and experimental groups, before playing the verses of the Quran $(p=.10)$ was not significant. The mean of mental health and all its domains, after hearing the verses of the
Quran, in experimental group was higher than the control group; it represents the positive effect of hearing the Quran on the mental health of participants. Diagram 1 shows the mean of mental health and its domains in the experimental and control groups before and after the playing verses of the Quran.

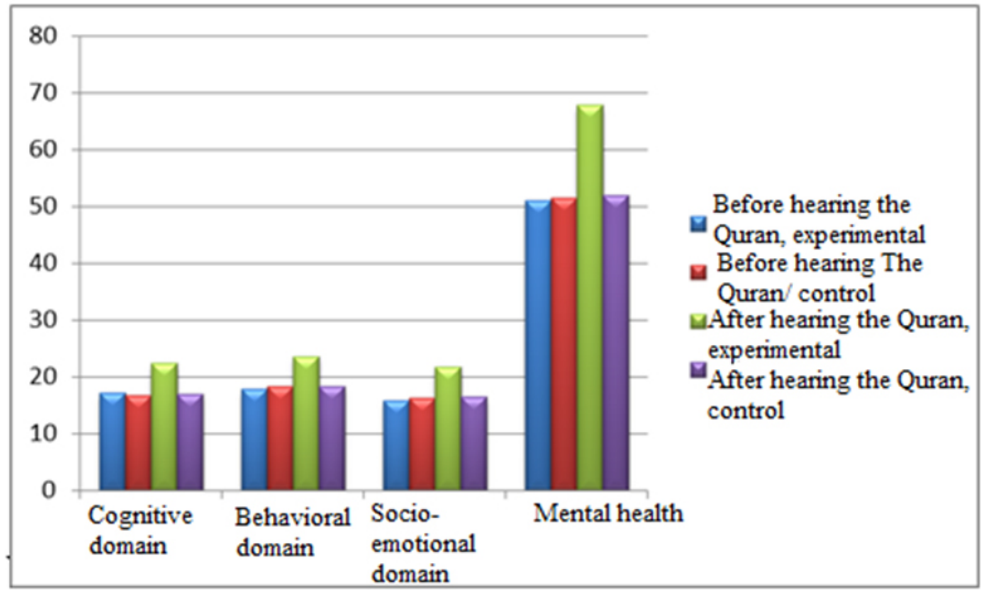

Figure 1. The mean of mental health and its domains in the experimental and control groups before and after the playing verses of the Quran 
As shown in Table 2, Levene's test was used to prove the equality of variances $(p>.05)$. Also Table 2 showed that mental health was significantly different between men and women after of interventions. Women indicated a higher average score than men on mental health, behavioral and socio emotional domains.

Table 2. Investigating the differences between components of mental health based on gender after the playing Quran verses for the experimental group

\begin{tabular}{|c|c|c|c|c|c|}
\hline Variable & Gender & Mean & $\begin{array}{l}\text { Equality of Variances } \\
\text { F (P) }\end{array}$ & $t$ & $p$ \\
\hline \multirow{2}{*}{ Cognitive } & Male & 22.21 & \multirow{2}{*}{$2.32(0.567)$} & \multirow{2}{*}{-1.18} & \multirow{2}{*}{.08} \\
\hline & Female & 21.67 & & & \\
\hline \multirow{2}{*}{ Behavioral } & Male & 19.49 & \multirow{2}{*}{$0.234(0.342)$} & \multirow{2}{*}{-5.38} & \multirow{2}{*}{$.001 *$} \\
\hline & Female & 23.38 & & & \\
\hline \multirow{2}{*}{ Socio emotional } & Male & 17.41 & \multirow{2}{*}{$0.546(0.289)$} & \multirow{2}{*}{6.78} & \multirow{2}{*}{$.001^{*}$} \\
\hline & Female & 2159 & & & \\
\hline \multirow{2}{*}{ Mental health } & Male & 63.87 & \multirow{2}{*}{$0.890(0.312)$} & \multirow{2}{*}{14.76} & \multirow{2}{*}{$.000^{*}$} \\
\hline & Female & 71.81 & & & \\
\hline
\end{tabular}

$* p<.05$

Considering Table 3, we can state that after hearing Quran recitation, there appeared to be a significant difference between the mean of mental health and all its domains in staffs (under the age of 40, between 40-50, over the age of 50). Therefore, the effect of listening to the Quran on mental health and its domains was not equal at different ages. Tak- ing Turkey's binary comparisons test, we concluded the mean of mental health and all its domains in the staffs between the ages of 40-50 was higher than the mean score of staffs younger than 40 and older than 50 . On the other hand, the score of mental health and all its domains at the age of 50 was higher than that of the staffs who were younger than 40 .

Table 3. The relationship between age and mental health after playing recitation of the Quran in the experimental group

\begin{tabular}{|c|c|c|c|c|}
\hline Variable & Age & Average & $\mathbf{F}$ & $p$ \\
\hline \multirow{3}{*}{ Cognitive } & Younger than the age of 40 & 18.72 & \multirow{3}{*}{2.32} & \multirow{3}{*}{$.001^{*}$} \\
\hline & Between 40 to 50 & 25.49 & & \\
\hline & Older than the age of 50 & 22.02 & & \\
\hline \multirow{3}{*}{ Behavioral } & Younger than the age of 40 & 19.88 & \multirow{3}{*}{5.234} & \multirow{3}{*}{$.001^{*}$} \\
\hline & Between 40 to 50 & 24.71 & & \\
\hline & Older than the age of 50 & 21.60 & & \\
\hline \multirow{3}{*}{ Socio emotional } & Younger than the age of 40 & 17.00 & \multirow{3}{*}{8.546} & \multirow{3}{*}{$.01^{*}$} \\
\hline & Between 40 to 50 & 21.59 & & \\
\hline & Older than the age of 50 & 19.91 & & \\
\hline \multirow{3}{*}{ Mental health } & Younger than the age of 40 & 55.6 & \multirow{3}{*}{17.890} & \multirow{3}{*}{$.001^{*}$} \\
\hline & Between 40 to 50 & 71.79 & & \\
\hline & Older than the age of 50 & 63.53 & & \\
\hline
\end{tabular}

$* p<.05$

\section{DiscuSSION}

Present study revealed the positive effect of hearing the Quran on the mental health of participants. Results of different studies also show that there is a significant relationship between spiritual understanding and mental health. ${ }^{[16,25,26]}$ Researches on "the effects of spirituality on health" have Published by Sciedu Press shown that spirituality is associated with lower amount of diseases and greater longevity. ${ }^{[27,28]}$ When faced with an injury, people who have spiritual orientations respond better to treatments and better cope with injuries and defects. ${ }^{[29]}$ Researches on the impact of Quran recitation on the anxiety and pain of patients undergoing surgeries also showed 
the positive impact of the Quran on the mental and physical health of patients. ${ }^{[30]}$ But it was the first study that was done on medical staffs. Kazemi et al. (2004) conducted a research on the impact of the Holy Quran on mental health of nursing students. Consistent with our study they reported the positive impact of the Quran on student's mental health. ${ }^{[31]}$ Mc McCarthy and colleagues (1998) studies the impact of music on mood, stress and mental health. They reported that regular music can relieve stress, mental disorders and negative mood. ${ }^{[32]}$

According to Taghi Lou and colleagues (2009), reading the Quran is effective in reducing stress of young people and adolescents. ${ }^{[33]}$ Moeini, et al. (2014) stated that the recitation of the Holy Quran is effective on the anxiety of patients admitted to the oncology care unit. ${ }^{[34]}$ Sharifnia, et al. (2016) also reported in their study that the recitation of the Holy Quran is effective in reducing anxiety and depression. ${ }^{[35]}$ Najafi, et al. (2014) reported the positive effect of the Holy Quran on depression, anxiety and stress. ${ }^{[36]}$ In all cases, the healing effect of the Holy Quran is remarkable; excessive stress can reduce resistance of the body making the patients prone to any physical and mental disease. The results of Sabry, et al. (2013) indicate the positive effect of the Holy Quran on the depressed patients of psychiatry department and are in line with the results of previous studies. ${ }^{[24]}$ Although psychiatric treatments in Iran mainly involve drugs (of course, the role of drugs in the treatment of mental health problems cannot be denied), they are not responsive to all mental health needs. Researchers believe that religion must be considered in most studies because they expect people with higher level of religious and connection with God to be happier life and more satisfied with their work. Improving the quality of mental health and working life in nurses and other staff is one of the most important ways to sustain the health system. ${ }^{[23]}$ In every organization, high level of mental health and quality of working life is necessary to attract employees. Since mental health will affect people's feeling about their workplace, assessment of quality of working life is essential. This issue in hospitals is very important because nurses are the largest group of workers in every hospital around the world.

In the present study, a significant difference was observed between men and women of the experimental group after playing Quran recitation, in terms of mental health in the behavioral and socio emotional domains. However, there

\section{REFERENCES}

[1] Kessler RC, Berglund PA, Chiu WT, et al. The Prevalence and Correlates of Binge Eating Disorder in the World Health Organization was no difference between men and women in the cognitive domain. As a result, the effect of playing the recitation of the Quran, was not the same between men and women; women indicated a higher average score than men on mental health, behavioral and socio emotional domains. The mean of mental health and all its domains in the staffs between the ages of 40-50 was higher than the mean score of staffs under 40 and over 50 .

\subsection{Limitations of study}

The major limitations of the present study were (i) limited sample size (couldn't access to medical staffs of other medical universities), (ii) cant controlling the effect of cultural differences between the participants of two groups, and (iii) probable listening of control group to Quran recitation that may limited the generality of the results.

\subsection{Recommendations for future researches}

Based on importance of the issue, recommended that (i) future studies be done with more details to earn trustable results, (ii) design the same studies with larger sample sizes, (iii) because of application of the results suggested that different groups be used for future studies.

\section{Conclusion}

Present study revealed the positive effect of hearing the Quran on the mental health of participants. As a final conclusion and on the basis of the findings of this study; it can be said, particularly in Muslim communities, hearing the Quran recitations improves the mental state of the people. In addition, regarding the close connection of the teaching staff with the students of the University of Medical Sciences, we can conclude that hearing the Quran can make the staff to feel more satisfied and do their tasks with more optimism; thus, the students will be pleased as well. Therefore, it is recommended to use the Quran recitations to reinforce positive emotions and psychological comfort for Muslim staffs.

\section{ACKNOWLEDGEMENTS}

The authors would like to thank the research team for their contribution to conducting this study. Also thanks to research deputy of Mazandaran University of medical sciences for their financial support.

\section{CONFLICTS OF INTEREST DISCLOSURE}

The authors declare that there is no conflict of interest.
World Mental Health Surveys. Biological Psychiatry. 2013; 73: 90414. PMid:23290497 https://doi .org/10.1016/j . biopsych.2 012.11 .020 
[2] Jamali S, Sabokdast S, Sharif Nia H, et al. The Effect of Life Skills Training on Mental Health of Iranian Middle School Students: A Preliminary Study. Iranian Journal of Psychiatry. 2016; 11: 269-72. PMid:28050189

[3] Lanata A, Valenza G, Nardelli M, et al. Complexity Index From a Personalized Wearable Monitoring System for Assessing Remission in Mental Health. IEEE Journal of Biomedical and Health Informatics. 2015; 19: 132-9. PMid:25291802 https ://doi .org/10.110 9/JBHI. 2014.2360711

[4] Skeem JL, Winter E, Kennealy PJ, et al. Offenders with mental illness have criminogenic needs, too: toward recidivism reduction. Law and human behavior 2014; 38: 212-24. PMid:24377913 https://doi.org/10.1037/1hb0000054

[5] Sharif Nia H, Pahlevan Sharif S, Goudarzian AH, et al. The Relationship between Religious Coping and Self-Care Behaviors in Iranian Medical Students. Journal of Religion and Health. 2017. PMid:28229351 https://doi.org/10.1007/s10943-017-037 6-2

[6] Heidari Gorji AM, Darabinia M, Ranjbar M. Relationship Between Emotional Intelligence and Job Motivation Among Faculty Staff in Mazandaran University of Medical Sciences, Iran. Iran J Psychiatry Behav Sci. Online ahead of Print;In Press(In Press): e8065.

[7] Gebauer JE, Nehrlich AD, Sedikides C, et al. The Psychological Benefits of Income are Contingent on Individual-Level and Culture-Level Religiosity. Social Psychological and Personality Science. 2013; 4: 569-78. https://doi.org/10.1177/1948550612469819

[8] Harvey AJ, Callan MJ. The role of religiosity in ultimate and immanent justice reasoning. Personality and Individual Differences. 2014; 56: 193-6. https://doi.org/10.1016/j.paid.2013.08.023

[9] Fakhar M, Darabinia M, Montazeri M. Some Islamic pattern in relation to food and water hygiene. The Turkish Online Journal of Design, Art and Communication. 2016.

[10] Webb J, Stouffer LE. Religious and Spiritual Differences Within Families: Influences on End-of-life Decision Making. The Journal for Nurse Practitioners. 2014; 10: 588-93. https ://doi .org/10 $.1016 / j$.nurpra. 2014.05.018

[11] Nesami MB, Goudarzian AH, Zarei H, et al. THE RELATIONSHIP BETWEEN EMOTIONAL INTELLIGENCE WITH RELIGIOUS COPING AND GENERAL HEALTH OF STUDENTS. Materia Socio-Medica. 2015; 27: 412-6. PMid:26889101 https: //doi.org/10.5455/msm.2015.27.412-416

[12] Unterrainer HF, Lewis AJ, Fink A. Religious/Spiritual Well-Being, Personality and Mental Health: A Review of Results and Conceptual Issues. Journal of Religion and Health 2014; 53: 382-92. PMid:22965652 https://doi .org/10.1007/s10943-012-964 2-5

[13] Darabinia M, Gorji AH, Gholami S. Self-care study in the Iranian medical students based on Islamic thought. Journal of Nursing Education and Practice. 2017; 7(9): 85. https://doi.org/10.5430/ jnep.v7n9p85

[14] Kovess-Masfety V, Evans-Lacko S, Williams D, et al. The role of religious advisors in mental health care in the World Mental Health surveys. Social Psychiatry and Psychiatric Epidemiology. 2016. 1-15 p.

[15] Darabinia M, Gorji AMH, Chabra A. Medicinal properties of pomegranate in Quran and Islamic Traditions (Hadith). International Journal of Humanities and Cultural Studies (IJHCS). 2016; 1: 1591601.

[16] Mahjoob M, Nejati J, Hosseini A, et al. The Effect of Holy Quran Voice on Mental Health. Journal of Religion and Health. 2016; 55: 38-42. PMid:24421119 https://doi.org/10.1007/s10943-0 14-9821-7

Published by Sciedu Press
[17] Boalhry RJ, Ferrand A. Koran and the ways to deal with mental stress The third national symposium on Stress; Tehran. 1995. p. 70.

[18] Hassanpour F, Loya MJ, editors. Quran recitation effect on reducing anxiety and depression. Proceedings of the conference on religion and mental health; 1997; Tehran.

[19] Jafari M, Mousavi Z, editors. Effect of continuance of the Quran recitation in coping with stress among female students in Qom city. Proceedings of the conference on religion and mental health; 1997; Tehran.

[20] Galedar N, Saki M. Avaye effect on reducing anxiety before the Koran students test. The first international conference on religion and mental health; Tehran. p. 194-230. PMid:27092214

[21] Aghababaei N, Tabik MT. Gratitude and mental health: differences between religious and general gratitude in a Muslim context. Mental Health, Religion \& Culture. 2013; 16: 761-6. https : //doi.org/10.1080/13674676.2012.718754

[22] Bromet EJ, Luft BJ. Consequences of toxic disasters for rescue, recovery, and clean-up workers require integrated mental and physical health monitoring. Social Psychiatry and Psychiatric Epidemiology. 2015; 50: 1761-3. PMid:26386714 https://doi.org/10.1007/ s00127-015-1124-0

[23] Bagheri-Nesami M, Kazemi A, Goudarzian AH, et al. Association Between Religious Coping and Quality of Working Life in Nurses. Iranian Journal of Psychiatry and Behavioral Sciences. 2017; 11: e4946.

[24] Sabry W, Vohra A. Role of Islam in the management of Psychiatric disorders. Indian Journal of Psychiatry. 2013; 55: 205-14 PMid:23858256 https://doi .org/10.4103/0019-5545.1055 34

[25] Weber SR, Pargament KI. The role of religion and spirituality in mental health. Current Opinion in Psychiatry. 2014; 27: 358-63. PMid:25046080 https://doi.org/10.1097/YC0.0000000000 000080

[26] Eltaiba N, Harries M. Reflections on Recovery in Mental Health: Perspectives From a Muslim Culture. Social Work in Health Care. 2015; 54: 725-37. PMid:26399491 https://doi.org/10.1080/ 00981389.2015 .1046574

[27] Koenig HG. Religion, spirituality, and health: a review and update Advances in Mind/Body Medicine. 2015; 29: 19-26. PMid:26026153

[28] Lavelock CR, Griffin BJ, Worthington EL. Forgiveness, Religiousness, Spirituality, and Health in People with Physical Challenges: A Review and a Model. Research in the Social Scientific Study of Religion: Brill; 2013. 53-92 p.

[29] Emmons RA. Is Spirituality an Intelligence? Motivation, Cognition, and the Psychology of Ultimate Concern. The International Journal for the Psychology of Religion. 2000; 10: 3-26. https: //doi.org/10.1207/S15327582IJPR1001_2

[30] Nasiri M, Naboureh A, Fayazi S. The Effect of an Islamic Praise (Zikr) on Postoperative Anxiety of Patients Undergoing Coronary Artery Bypasses Graft Surgery: A Randomized Clinical Trial on Iranian Shia Muslims. Research in Cardiovascular Medicine; Inpress: e41388.

[31] Kazemi M, Ansari A, Allah Tavakoli M, et al. The Effect of the Recitation of Holy Quran on Mental Health in Nursing Students of Rafsanjan University of Medical Sciences. Journal of Rafsanjan University of Medical Sciences. 2004; 3: 52-7.

[32] McCraty R, Barrios-Choplin B, Atkinson M, et al. The effects of different types of music on mood, tension, and mental clarity. Alternative Therapies in Health and Medicine. 1998; 4: 75-84 PMid:9439023

[33] Loue ST. Effect on reducing stress in the Quran reading among youth Journal of Guilan University of Medical Sciences. 2009; 18: 72-81. 
[34] Moeini M, Taleghani F, Mehrabi T, et al. Effect of a spiritual care program on levels of anxiety in patients with leukemia. Iranian Journal of Nursing and Midwifery Research. 2014; 19: 88-93.

[35] Sharifnia M, Hasanzadeh MH, Asadi Kakhaki SM, et al. The Impact of Praying on Stress and Anxiety in Mothers with Premature Infants
Admitted to NICU. Iranian Journal of Neonatology. 2016; 7: 15-22.

[36] Najafi Z, Tagharrobi Z, Lotfi MS, et al. Effect of recitation of Quran on the anxiety of patients with myocardial infarction. Evidence Based Care. 2014; 4: 7-16. 